\title{
ABNORMAL LOW LINEWIDTH TEMPERATURE BROADENING OBSERVED FOR YVO4:Eu NANOCRYSTALS
}

\author{
P.O. MAKSIMCHUK, A.A. MASALOV, V.V. SEMINKO, O.G. VIAGIN, \\ V.K. KLOCHKOV, YU.V. MALYUKIN
}

PACS 78.55.Hx (C) 2012
Institute for Scintillation Materials, Nat. Acad. of Sci. of Ukraine

(60 Lenin Ave, Kharkiv 61001, Ukraine; e-mail: pmaksimchuk@isma. kharkov. ua)
Since the temperature broadening of spectral lines is determined by the phonon scattering by impurity centers, a modification of the phonon spectrum can affect the temperature broadening suppression. So, by controlling the nanocrystal size, the effect of "cluster freezing," namely, the abnormal temperature broadening of weak spectral lines up to room temperature, can be achieved. The spectral lines of impurity ions in YVO4:Eu3 + nanocrystals remain abnormally narrow $\left(10 \mathrm{~cm}^{-1}\right)$ even at room temperature, whereas, for the bulk crystals, the average linewidth at room temperature is $70 \mathrm{~cm}^{-1}$. This narrowness of spectral lines can be clearly explained by the manifestation of the phonon spectrum depletion in nanocrystals. The temperature dependences of linewidths obtained for nanocrystals with various sizes exhibit the strong dependence of the spectral line width on the sizes of a nanocrystal and differ from those for a bulk crystal.

\section{Introduction}

The electron-phonon interaction (EPI) [1] as a ubiquitous fundamental effect of condensed-matter physics has been transformed nowadays into a potentially useful tool for the creation of modern materials with constitutive functional properties (such as photoswitches [2,3], phase shifting materials GeSbTe [4, 5], high-temperature superconductors $[6,7])$. There are several manifestations of EPI for impurity centers situated in solid matrices. At first, EPI provides the ultra-fast relaxation of excited electronic states for impurity centers [8]. For rare-earth (RE) ions, for instance, EPI provides the relaxation between Stark components of split terms and the terms themselves $[9,10]$. In addition, EPI leads to a temperature broadening and a spectral shift of spectral lines corresponding to the optical transitions in impurity centers $[11,12]$. In the low-temperature range, the temperature broadening makes an additive contribution to the homogeneous width of a spectral line hidden inside the inhomogeneous broadened spectral profile [10]. On the contrary, at room temperature, the phonon scattering on the impurity center makes a dominating contribution to the homogeneous width of a spectral line exceeding the in- homogeneous broadened profile [11-13]. The decrease of the crystal size up to few nanometers manifests itself in a significant modification of the phonon density of states. In the case of rare-earth doped nanocrystals, this effect can lead to the suppression of the phonon scattering contribution to the homogeneous widths of the spectral lines of doped ions. So, by controlling the nanocrystal size, the abnormal temperature broadening of weak spectral lines up to room temperatures can be achieved. The narrowness of the spectral lines of impurity ions in YSO:Pr nanocrystals at room temperature was shown in [14-15]. This narrowness was explained as a manifestation of the phonon spectrum depletion in nanocrystals. In this paper, the abnormally narrow spectral lines of impurity Eu3 + ions in YVO4:Eu3 + nanocrystals observed even at room temperature are measured. The narrow optical resonances have been analyzed, and the tentative explanation based on the manifestation of the quantum size effect in the phonon subsystem of nanocrystals is found. At first, the dependence of the spectral line width on the nanocrystal size is demonstrated.

\section{Experiment}

YVO4:Eu3 + nanocrystals were synthesized by means of the colloidal precipitation method. In the synthesis of YVO4:Eu3 + water colloidal solutions, chlorides of corresponding rare-earth elements (99.9), sodium metavanadate (96), Trilon B, and distilled water were used. Aqueous solutions of rare-earth chlorides were mixed with disodium edetate in the equivalent ratio. Then the equivalent amount of sodium orthovanadate was poured dropwise into a solution. The mixture was stirred intensively on a magnetic stirrer until bleaching. The solution was heated in a thermostat at $90{ }^{\circ} \mathrm{C}$ for $30-90 \mathrm{~min}$. After that, the solution was dialyzed for $24 \mathrm{~h}$ with a membrane of $12 \mathrm{KDa}$ (pore size of about $2.5 \mathrm{~nm}$ ). Changing the synthesis conditions such as the temperature, time, $\mathrm{pH}$ [16], and the ratio of EDTA/Re [17] significantly affects the size of colloidal particles in a solution. The synthe- 


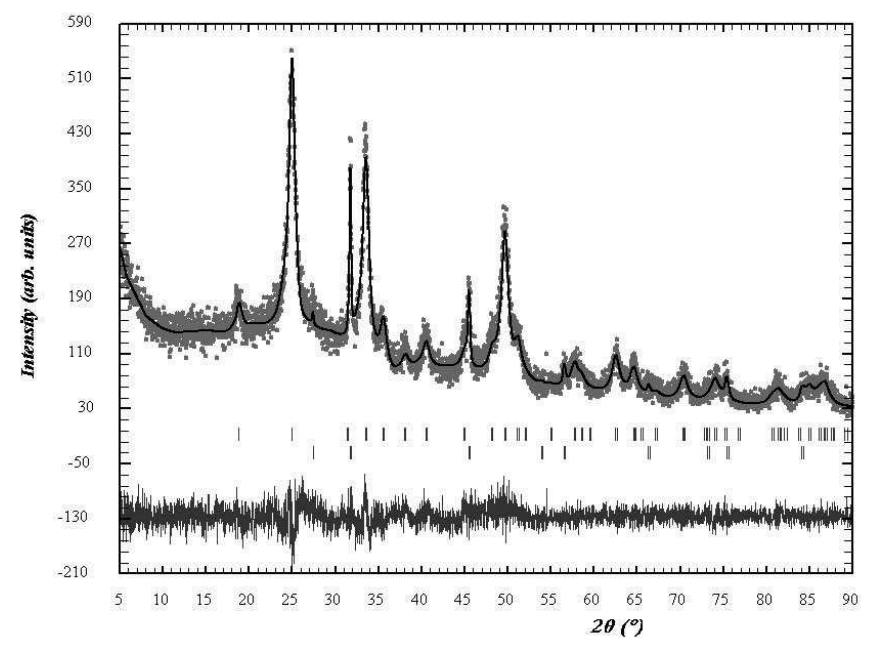

Fig. 1. XRD of the synthesized powder

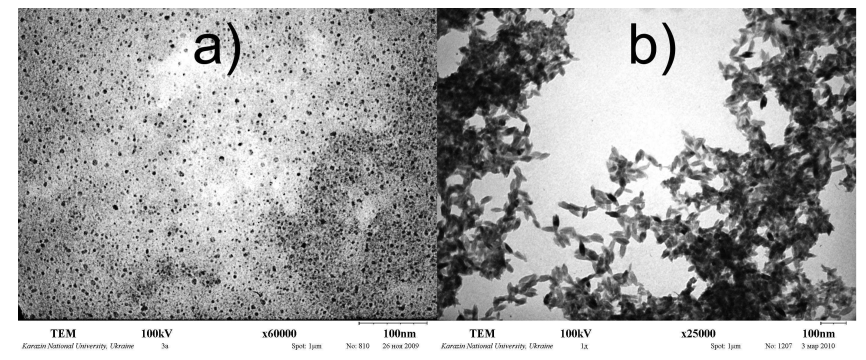

Fig. 2. TEM images of synthesized YVO:Eu nanoparticles. The average particle size $-5 \mathrm{~nm}(a)$ and $30 \mathrm{~nm}(b)$, respectively

sis of colloidal solutions was carried out in a thermostat at $90{ }^{\circ} \mathrm{C}$ for 30 and $40 \mathrm{~min}$, the other conditions being the same. As a result, the solutions with particles 5 and $30 \mathrm{~nm}$ in size, respectively, were obtained. After the synthesis, solutions were evaporated at $T=70{ }^{\circ} \mathrm{C}$. As a result, fine-dispersed powders were obtained. After the drying, the powders were annealed at $T=1000{ }^{\circ} \mathrm{C}$. The luminescence spectra of YVO:Eu nanocrystals have been investigated with a specially created spectrofluorimeter based on a grid monochromator SDL-1. The reciprocal linear dispersion of a monochromator SDL1 is equal to $1.6 \mathrm{~nm} / \mathrm{mm}$. The registration of spectra was carried out by a FEU-100, operating in the photon counting mode. The luminescence was excited by a helium-cadmium laser at $325 \mathrm{~nm}$. The possibility of a temperature variation was obtained, by placing the sample in a thermostat.

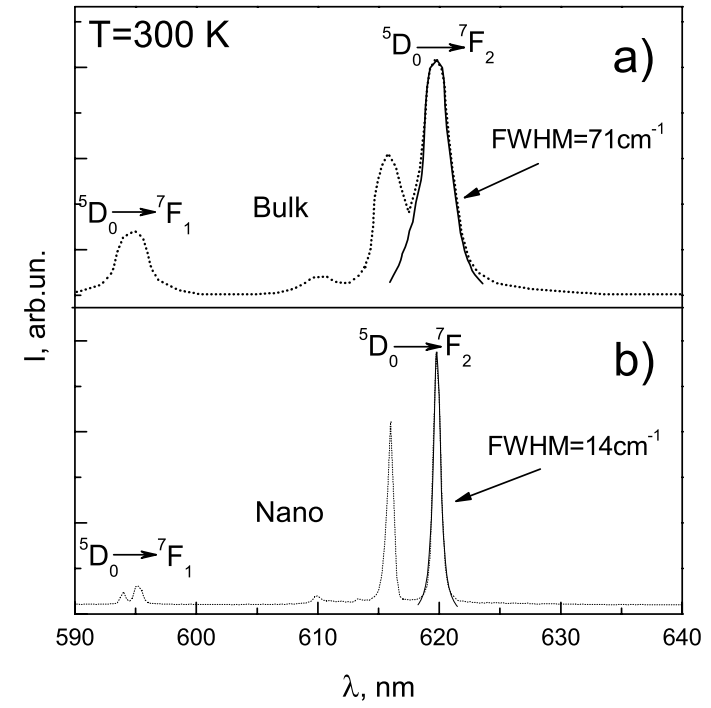

Fig. 3. Luminescence spectra of YVO:Eu bulk $(a)$ and nanocrystals $(b)$

\section{Experimental Results and Discussion}

By means of the colloidal precipitation, the samples of YVO4:Eu3 + (with different sizes, but similar in all other respects) have been synthesized. XRD of the synthesized nanocrystals is shown in Fig. 1. As a result, two groups of nanoparticles with average diameters of $5 \mathrm{~nm}$ and 30 $\mathrm{nm}$, respectively, with a narrow size distribution were synthesized. The particle size distributions do not overlap (Fig. 2).

In Fig. 3,a, the luminescence spectrum of a YVO:Eu bulk crystal at room temperature is shown [18]. The spectral lines are sufficiently broadened $\left(\mathrm{FWHM}=71 \mathrm{~cm}^{-1}\right) . \quad$ In Fig. 3,b, we present the luminescence spectrum of synthesized YVO:Eu nanocrystals at room temperature. We note that, in the case of YVO:Eu nanocrystals, the spectral lines of impurity ions in the luminescence spectrum remain narrow even at room temperature $\left(\mathrm{FWHM}=14 \mathrm{~cm}^{-1}\right)$, and the spectrum is similar to the spectrum of the YVO:Eu bulk crystal under the effect of deep cooling.

In order to determine the mechanism of broadening of spectral lines, we studied the temperature dependence of linewidths for particles with different sizes. These dependences for YVO:Eu nanocrystals with sizes of $5 \mathrm{~nm}$ and $30 \mathrm{~nm}$ are shown in Fig. 4. The curves clearly show that the temperature dependences of linewidths are significantly different for nanoparticles of different sizes.

Spectral lines in the absorption and luminescence spectra of impurity RE ions in bulk crystals at a low tem- 


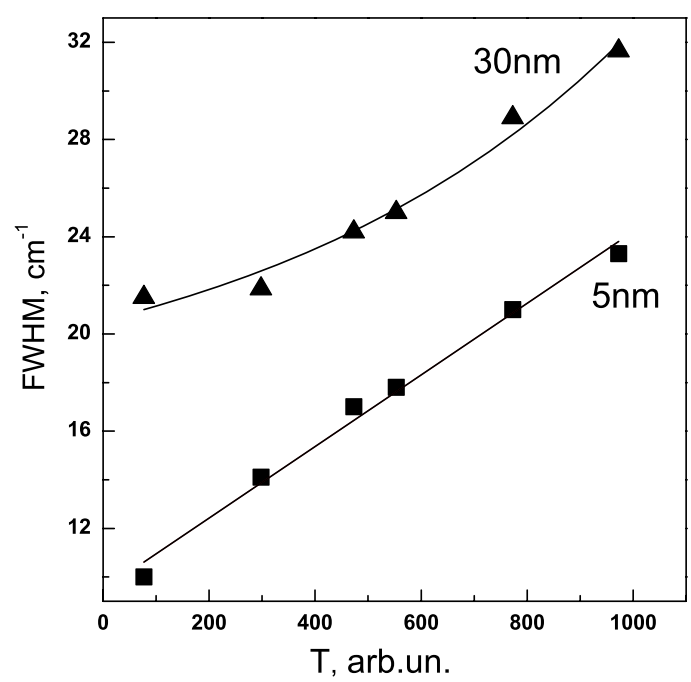

Fig. 4. Linewidth temperature dependences of the 5D0-7F2 Eu3+ impurity ion optical transitions for YVO:Eu nanoparticles with sizes of $5 \mathrm{~nm}$ and $30 \mathrm{~nm}$, respectively

perature are inhomogeneously broadened. The growth of the temperature leads to increasing the phonon scattering contribution to the homogeneous linewidth. At room temperature, the phonon scattering contribution becomes determinative, and the spectral lines are homogeneously broadened. In the general case, the contribution of the phonon scattering processes to a homogeneous linewidth is determined by the expression [12]

$\gamma(T)=\int(d \omega / 2 \pi) \ln \left\{1+W^{2} \rho^{2}(\omega) \operatorname{sh}^{-2}(\hbar \omega / k T)\right\}$,

where $W$ is the constant of electron-phonon coupling for the impurity center, $\rho$ is the phonon state density; $\hbar$ is the Planck constant; $k$ is the Boltzmann constant; and $T$ is the temperature. Expression (1) remains correct independently of the crystal size. The constant of electron-phonon coupling is determined only by the ligand field structure. As one can see in Fig. 5, the microscopic arrangement of an impurity center, as well as the shape and the position of spectral lines, is not changed with changing the nanocrystal size. So, the constant of electron-phonon coupling for the impurity center is independent of the crystal size.

The main parameter in expression (1) critically dependent on the crystal size in the nanometer range is the phonon density [19]. A depletion of the nanocrystal phonon state density leads to the suppression of the fast nonradiative relaxation of excited electron states at the impurity center [20]. In addition, the high-quality of nanocrystal vibrational modes with low anharmonicity was shown in $[21,22]$. The phonon mode quan-

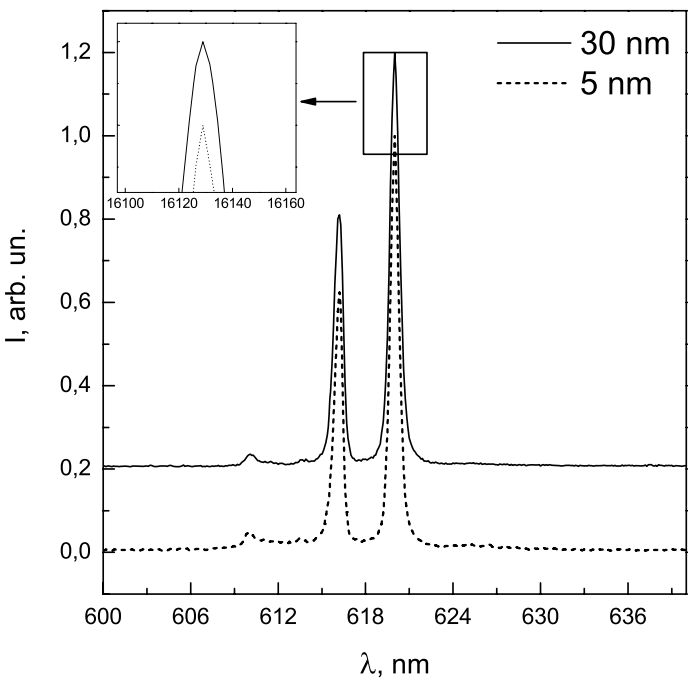

Fig. 5. Luminescence spectra of YVO:Eu nanocrystals with average size of particles to be $5 \mathrm{~nm}$ and $30 \mathrm{~nm}$

tity in a nanocrystal becomes explicitly discrete, and these modes can be expressed as the set of functions $\rho(\omega)=1 /\left(\left(\omega-\omega_{i}\right)^{2}+\left(2 \tau_{\mathrm{ph}}\right)^{-2}\right)$, where $\omega_{i}$ and $\tau_{\mathrm{ph}}$ are the frequency and decay time of the phonon mode, respectively. Thus, at $\tau_{\mathrm{ph}} \rightarrow \infty$, the integration in (1) is performed with $\delta$-functions leading to the minimization of $\gamma$. According to our interpretation, increasing the nanocrystal size must lead unambiguously to increasing the phonon density, which manifests itself in the growth of the phonon contribution to the impurity ion homogeneous linewidth. The experimental results (Fig. 4) totally confirm our predictions. Spectral lines in the impurity luminescence spectrum of YVO4:Eu3 + nanocrystals are broaden, as the nanocrystal size increases.

\section{Conclusions}

Rare-earth doped nanocrystals of wide-gap dielectrics exhibit narrow optical resonances of impurity ions even at room temperature. This effect is attributed to the weakening of the impurity center phonon scattering owing to the size effect action in the nanocrystal phonon subsystem.

1. E.M. Lifshitz and L.P. Pitaevskii, Physical Kinetics (Pergamon Press, Oxford, 1981).

2. P. Belser, S. Bernhard, and C. Blum, Coord. Chem. Rev. 190-192, 155 (1999).

3. A. Yassar, N. Rebiere-Galy, and M. Frigoli, Synth. Metals 124, 23 (2001).

4. S.R. Ovshinsky, J. of Non-Cryst. Sol. 141, 200 (1992). 
5. T. Shintani, K. Nakamura, and S. Hosaka, Ultramicrosc. 61, 285 (1995).

6. M.L. Kulic, Phys. Rep. 338, 1 (2000).

7. D. Tang, J. Li, and C. Gong, Phys. Lett. A 327, 344 (2004).

8. N. Terzi and M. Dominoni, in Ultrafast Dynamics of Quantum Systems. Physical Processes and Spectroscopic Techniques, edited by B. di Bartolo and G.Gambarota (Plenum Press, New York, 2002), p. 569.

9. A.A. Kaminskii, Physics and Spectroscopy of Crystals (Nauka, Moscow, 1986) (in Russian).

10. Spectroscopy of Solids Containing Rare Earth Ions, edited by A.A. Kaplyanskii and R.M. Macfarlane (NorthHolland, Amsterdam, 1987).

11. A.F. Lubchenko, Quantum Transitions in Impurity Centers of Solids (Naukova Dumka, Kiev, 1978) (in Russian).

12. I.S. Osad'ko, Phys. Rep. 206, 43 (1991).

13. A.M. Stoneham, Theory of Defects in Solids (Clarendon Press, Oxford, 1975).

14. Yu.V. Malyukin, A.A. Masalov, and P.N. Zhmurin, Phys. Lett. A 316, 147 (2003).

15. Yu.V. Malyukin, A.A. Masalov, and P.N. Zhmurin, Opt. Commun. 239, 409 (2004).

16. A. Huignard, V. Buissette, G. Laurent et al., Chem. Mater. 14, 2264 (2002).

17. G. Yi, H. Lu, S. Zhao, Y. Ge, W. Yang, D. Chen, and L.-H. Guo, Nano Lett. 4, 2191 (2004).

18. G. Jia, Y. Song, M. Yang, K. Liu, Y. Zheng, and H. You, J. of Cryst. Growth 311, 4213 (2009).
19. X.Y. Chen, H.Z. Zhuang, and G.K. Liu, J. of Appl. Phys. 94, 5559 (2003).

20. R.S. Meltzer, W.M. Yen, and H. Zheng, J. of Luminesc. 94-95, 217 (2001).

21. Yu.V. Malyukin, R.S. Borisov, and P.N. Zhmurin, Fiz. Nizk. Temp. 26, 132 (2000).

22. Yu.V. Malyukin, P.N. Zhmurin, A.N. Lebedenko et al., Fiz. Nizk. Temp. 28, 73 (2002).

Received 20.09.11

\section{НАДНИЗЬКЕ ТЕМПЕРАТУРНЕ \\ УШИРЕННЯ СПЕКТРАЛЬНИХ ЛІНІЙ, \\ ЩО СПОСТЕРІГАЄТЬСЯ У НАНОКРИСТАЛІ ҮVО:Еu}

П.О. Максимчук, А.А. Масалов, В.В. Семінко, О.Г. Вягін, В.К. Клочков, Ю.В. Малюкін

Р е $з$ ю м е

Оскільки температурне розширення спектральних ліній визначається розсіюванням фононів, модифікація фононного спектра може погасити температурне розширення. Таким чином, змінюючи розмір нанокристала можна спостерігати ефект "кластерного заморожування" - надслабке температурне уширення спектральних ліній аж до кімнатної температури. Спектральні лінії домішкових іонів у нанокристалах YVO:Eu3+ зберігають малу ширину $\left(10 \mathrm{~cm}^{-1}\right)$ навіть при кімнатній температурі, тоді як для об'ємного кристала середня ширина становить $70 \mathrm{~cm}^{-1}$. Така вузькість спектральних ліній може бути чітко пояснена проявом виснаження спектра фононів у нанокристалах. Температурне уширення спектральних ліній, що спостерігається для нанокристалів, залежить від розміру нанокристала і є іншим в об'ємних кристалах. 